\title{
Myocardial Blood Flow Distribution during Ischemia- Induced Coronary Vasodilation in the Unanesthetized Dog
}

\author{
Robert J. Bache, Frederick R. Cobb, and Joseph C. Greenfield, Jr. \\ From the Veterans Administration Hospital, Durham, North Carolina 27705, \\ and the Department of Medicine, Division of Cardiology, Duke University \\ Medical Center, Durham, North Carolina 27710
}

A B S TRACT This study was designed to determine whether coronary vasodilation distal to a flow-limiting coronary artery stenosis could result in redistribution of myocardial blood flow to produce subendocardial underperfusion. Studies were performed in 10 awake dogs chronically prepared with electromagnetic flowmeters and hydraulic occluders on the left circumflex coronary artery. Regional myocardial blood flow was measured using radionuclide-labeled microspheres, 7$10 \mu \mathrm{m}$ in diameter, injected into the left atrium. A 5-s coronary artery occlusion was followed by reactive hyperemia with excess inflow of arterial blood effecting $375 \pm 20 \%$ repayment of the blood flow debt incurred during occlusion. When, after a 5-s occlusion, the occluder was only partially released to hold arterial inflow to the preocclusion level for $20 \mathrm{~s}$ before complete release, the delayed reactive hyperemia was augmented (mean blood flow debt repayment $=610 \pm 45 \%, P<$ $0.01)$. This augmentation of the reactive hyperemia suggested that ischemia was continuing during the interval of coronary vasodilation when coronary inflow was at the preocclusion level. Measurements of regional myocardial blood flow demonstrated that endocardial flow slightly exceeded epicardial flow during control conditions. When arterial inflow was limited to the preocclusion rate during vasodilation after a 5-s total coronary artery occlusion, however, flow to the subepicardial myocardium was increased at the expense of underperfusion of the subendocardial myocardium. Thus, in the presence of a flow-limiting proximal coro-

This study was presented in part at the 46th Scientific Session of The American Heart Association, Atlantic City, N. J., 10 November 1973.

Doctnrs Bache and Cobb are Clinical Investigators, Veter?ns Administration Hospital, Durham, N. C. Dr. Greenfield is the recipient of Research Career Development Award 1-K3-HL-28112 from the U. S. Public Health Service.

Reccived for publication 17 April 1974 and in revised form 2 August 1974. nàry artery stenosis, ischemia-induced coronary vasodilation resulted in redistribution of myocardial blood flow with production of subendocardial ischemia in the presence of a net volume of arterial inflow which, if properly distributed, would have been adequate to prevent myocardial ischemia.

\section{INTRODUCTION}

During systole, intramyocardial tissue pressure resulting from cardiac contraction acts to impede intramural coronary flow. Since systolic tissue pressure across the left ventricular wall increases from epicardium to endocardium, maximum impedance to flow occurs near the endocardial surface, whereas p'erfusion of more superficial layers of myocardium is variably maintained in proportion to the depth of the muscle layer (1-3). Uniform net transmural myocardial perfusion is maintained by compensatory augmentation of subendocardial perfusion during diastole which occurs in proportion to the degree of systolic underperfusion (4). Maintenance of this diastolic perfusion gradient favoring the subendocardium depends upon active coronary vasomotion maintaining vascular resistance lower within the subendocardium than in the subepicardium, and sufficient arterial inflow during diastole to effect distribution of blood in proportion to the resistance of the precapillary vessels $(4,5)$. It is possible that ischemia may impair the ability of the coronary microvasculature to maintain this normal diastolic gradient of vascular resistance. This would appear especially likely in the presence of a proximal flow-limiting coronary artery stenosis which would limit the increase of coronary inflow which could occur in response to dilation of the distal coronary vasculature.

This study was designed to examine the distribution of myocardial blood flow which results when coronary vasodilation is produced by an ischemic stimulus, but coronary artery inflow is prevented from increasing above the control level by a flow-limiting proximal 
coronary artery stenosis. It was anticipated that such ischemia-induced coronary vasodilation would compromise the ability of active coronary vasomotion to determine uniform myocardial perfusion, and would result in subendocardial underperfusion despite inflow of a normal net volume of coronary artery blood. The reactive hyperemic response, which bears a constant relationship to the degree of preceding ischemia, was used to quantitatively evaluate whether the observed redistribution of myocardial blood flow did in fact result in significant regional myocardial ischemia $(6,7)$. All studies were performed in chronically instrumented unanesthetized dogs to eliminate possible interfering effects associated with general anesthesia and acute surgical trauma.

\section{METHODS}

10 adult mongrel dogs weighing $20-32 \mathrm{~kg}$ were anesthetized with sodium thiamylal $(30-40 \mathrm{mg} / \mathrm{kg}$ i.v.) and underwent left thoracotomy. The proximal $1.5 \mathrm{~cm}$ of the circumflex branch of the left coronary artery was dissected free, and an electromagnetic flowmeter probe $^{1}$ was positioned around the vessel proximal to any branches. Care was taken to attain mechanical stability of the flow probe on the coronary artery to ensure a consistently stable base line during later coronary flow measurements (8). A pneumatic occluder constructed in our laboratory of polyvinyl chloride tubing with a $2.7-\mathrm{mm}$ outside diameter was placed around the circumflex coronary artery distal to the electromagnetic flow probe (9). A heparin-filled polyvinyl chloride catheter with a 3-mm outside diameter was introduced into the arch of the aorta via the left internal mammary artery. A similar catheter was introduced into the left atrial cavity through the left atrial appendage and secured in place with a purse-string suture. The electromagnetic flowmeter leads, aortic and left atrial catheters, and hydraulic occluder tube were tunneled dorsally into a subcutaneous pouch at the base of the neck but were not exteriorized to protect them from damage. The flowmeter leads, catheters, and occluder tube were exteriorized through a $1-\mathrm{cm}$ skin incision using $2 \%$ lidocaine infiltration anesthesia the morning before study.

Throughout this report, the phrase "coronary blood flow" will denote measurements of flow through the circumflex branch of the left coronary artery. Coronary flow was measured using Statham M-4000 electromagnetic flowmeters. ${ }^{1}$ Flowmeter calibrations performed by passing measured flows of normal saline through the flowmeter probes remained within a standard deviation of not more than $\pm 7 \%$ during the period of study. Aortic and left atrial blood pressures were measured using Statham P23Db pressure transducers. ${ }^{1}$ Lead 2 of a standard electrocardiogram was obtained. Data were recorded using an eight-channel magnetic tape recorder (model 3917-A) ${ }^{2}$ and an eightchannel direct-writing oscillograph (model 8800 ). ${ }^{2}$

Studies were carried out 13-36 days after the initial surgery. All animals were active and fully recovered from surgery without fever or other evidence of ill health. At the time of study hematocrits ranged from 37 to $47 \%$. Animals were trained to lie quietly on their right sides

${ }^{1}$ Statham Instruments, Inc., Oxnard, Calif.

'Hewlett-Packard Co., Palo Alto, Calif. during study. The laboratory was dimly illuminated and kept free of noise or other activity which might disturb the dog. Coronary artery occlusions were performed by abruptly injecting and holding $1 \mathrm{ml}$ of water into the occluder tubing with a hand-held syringe while the electromagnetic flowmeter tracing was observed to insure total cessation of coronary blood flow. Examination of recordings of coronary blood flow made at a paper speed of $100 \mathrm{~mm} / \mathrm{s}$ demonstrated that this technique allowed complete occlusion or controlled release of the occlusion within $0.1 \mathrm{~s}$. After all recording instruments were connected, a 60-s coronary artery occlusion was produced while lead II of the electrocardiogram was monitored. All dogs exhibited significant elevation of the S-T segment during this occlusion, as well as increased heart rate, indicating absence of an effective coronary collateral circulation which might impair the ischemic stimulus produced by a coronary artery occlusion during subsequent studies. Subsequently, a 45-60min interval was allowed for the animal to adjust to the laboratory conditions. During this time, data were sampled continuously to ensure that a control steady state had been achieved.

The reactive hyperemic response was observed after coronary artery occlusions of 5-s duration. All responses were observed in triplicate and the mean of the three responses used for subsequent computations. Within the same dog, the mean difference in debt repayments observed between consecutive reactive hyperemias was $10 \%$, with a $95 \%$ probability that consecutive debt repayments would differ by less than $21 \%$. A minimum of $2 \mathrm{~min}$ was allowed from the end of a reactive hyperemic response until the subsequent coronary artery occlusion was performed. Reactive hyperemic responses were then observed when a 5-s total coronary occlusion was performed and a sufficient volume of water subsequently withdrawn from the occluder to allow coronary flow to return to the preocclusion rate of flow. Studies were discarded if coronary flow during this interval deviated from the preocclusion control rate by more than 5\%. After this interval of restricted inflow, either 20 or $60 \mathrm{~s}$ in duration, the occluder was completely released to allow the reactive hyperemic response. The sequence in which occlusions were performed was randomized, and each intervention was performed in duplicate. Every third intervention was a simple 5-s coronary artery occlusion to insure that the reactive hyperemic response after a 5-s occlusion remained constant.

Studies were discarded in which heart rate or arterial blood pressure differed by more than $5 \%$ from the control value during the occlusion and to the end of the reactive hyperemic response. The systolic and diastolic fractions of coronary flow were obtained by electrical integration using an analog computer (model 8815A). ${ }^{2}$ Systolic flow was taken as the interval corresponding to left ventricular ejection measured from the aortic pressure tracing. The volume of flow occurring during the reactive hyperemia after a coronary artery occlusion was determined by electrical integration. The duration of the hyperemic period was taken as the time required for flow to fall to within $5 \%$ of the control measurement. Calculations of blood flow debt incurred during arterial occlusion, reactive hyperemic flow, and blood flow debt repayments were made as described by Freeman (10): Blood flow debt (milliliters) = control flow rate (milliliters per second) $\times$ duration of occlusion (seconds). Reactive hyperemic flow (milliliters) $=$ [total flow during reactive hyperemia (milliliters)]-[control flow rate (milliliters per second) $X$ duration of reactive 
hyperemia (seconds)]. Blood flow debt repayment (percent $)=($ reactive hyperemic flow/blood flow debt) $\times 100$.

Measurements of distribution of myocardial blood flow were made by injecting into the left atrium carbonized microspheres $7-10 \mu \mathrm{m}$ in diameter labeled with gamma-emitting nuclides ${ }^{141} \mathrm{Ce},{ }^{85} \mathrm{Sr}$, or ${ }^{18} \mathrm{Sc}^{3}$ The microspheres were obtained as $1.0 \mathrm{mCi}$ of each nuclide in $10 \mathrm{ml}$ of $10 \%$ dextran and $0.05 \%$ polysorbate- 80 . This stock solution was diluted in $10 \%$ dextran so that $1.0 \mathrm{ml}$, the volume injected, contained approximately 2 million microspheres. This dosage was selected so that during control conditions, each gram of myocardium would receive a minimum of 500 microspheres, i.e., assuming a coronary blood flow of $5 \%$ of the cardiac output and heart weight $150-200 \mathrm{~g}$. Injection of this quantity of microspheres resulted in no change in heart rate during the interval of injection, and resulted in no change in arterial or left atrial pressure measured immediately before and immediately after collection of the reference blood sample. Before injection, microspheres were mixed by alternate agitation for at least $15 \mathrm{~min}$ in an ultrasonic bath (model DA0950) ${ }^{3}$ and a vortex agitator. Complete dispersion of microspheres was verified by examining a drop of microsphere suspension with a light microscope before injection.

In each dog $1.0-\mathrm{ml}$ microsphere suspension was injected into the left atrium during resting control conditions and the atrial catheter was then flushed with $3 \mathrm{ml}$ of normal saline. This injection and all subsequent microsphere injections were made over a 5-s interval. To evaluate the distribution of myocardial blood flow during coronary reactive hyperemia, a second injection of $1.0 \mathrm{ml}$ of microsphere suspension labeled with a different radionuclide was injected beginning $5 \mathrm{~s}$ after release of a 5-s coronary artery occlusion in seven dogs. Finally, to study distribution of myocardial blood flow when coronary vasodilation was produced by an ischemic stimulus, but coronary inflow prevented from increasing above the control level, a 5-s coronary artery occlusion was produced and the occluder then partially deflated to allow coronary flow to return to the preocclusion control level of flow, but to prevent any reactive hyperemia in 10 dogs. Beginning $5 \mathrm{~s}$ after restoration of coronary artery inflow to the control rate, $1.0 \mathrm{ml}$ of microsphere suspension labeled with a third radionuclide was injected into the left atrium. Coronary artery flow was maintained at the preocclusion rate for an additional $30 \mathrm{~s}$ to ensure complete dispersion of microspheres before the occluder was completely released. Beginning simultaneously with each microsphere injection and continuing for $90 \mathrm{~s}$, a reference sample of arterial blood was collected from the aortic catheter at a constant rate of $15 \mathrm{ml} / \mathrm{min}$ using a withdrawal pump."

After completion of study, the animal was sacrificed with a lethal dose of pentobarbital and the heart removed and fixed in $10 \%$ buffered formalin. The atria, right ventricle, aorta, and large epicardial blood vessels were dissected from the left ventricle and discarded. The left ventricle was then sectioned into four transverse sections of approximately equal thickness parallel to the mitral valve ring as previously described (11). The two central sections which constituted $54 \pm 6 \%$ of the left ventricular weight were used for study. Four full-thickness tissue blocks, each encompassing approximately $1.5 \mathrm{~cm}$ of the outer circumference of each of the two central sections, were removed from the anterior left ventricular free wall, anterior papillary

3 Co., St. Paul, Minn.

- Model 1210, Harvard Apparatus Co., Millis, Mass. muscle region, posterior left ventricular free wall, and posterior papillary muscle region. Since injections of methylene blue into the circumflex coronary artery demonstrated myocardial staining within a distribution encompassing the posterior left ventricular free wall and posterior left ventricular papillary muscle tissue blocks, these specimens were taken to represent the myocardial regions under study, whereas the two corresponding anterior specimens served as controls. Each tissue block was divided into equal outer (epicardial) and inner (endocardial) layers, weighed, and placed in vials for counting. Mean weight of the epicardial specimens was 2.09 \pm SD $0.48 \mathrm{~g}$ (range $1.21-4.00 \mathrm{~g}$ ), and mean weight of the endocardial specimens was $1.83 \pm 0.56 \mathrm{~g}$ (range $0.83-3.33 \mathrm{~g}$ ). Only one specimen weighed less than $1.0 \mathrm{~g}$.

Radioactivity was determined with a gamma spectrometer (model 167776) ${ }^{5}$ using window settings which corresponded to the peak energies emitted by each radioactive nuclide. The activities recorded in each energy window and the corresponding sample weights were then entered into a digital computer (1130) ${ }^{\circ}$ programmed to correct activity recorded in each window for contaminant activity contributed by the associated nuclides and for background activity, and to compute the corrected counts per minute per gram of myocardium. Knowing the rate of withdrawal of the reference sample $\left(Q_{r}\right)$ and the radioactivity $\left(C_{r}\right)$ in the reference sample, and knowing that the ratio of flow and radioactivity are uniform throughout because complete mixing of microspheres with blood occurred during passage through the left ventricle, myocardial radioactivity $\left(C_{m}\right)$ was used to compute myocardial blood flow $\left(Q_{m}\right)$ as :

$$
Q_{m}=Q_{r} \cdot C_{m} / C_{r}
$$

Data analysis using Student's $t$ test for paired data was performed using a digital computer.

\section{RESULTS}

Mean heart rate was 74士SEM 6 beats/min (range 58-104 beats $/ \mathrm{min}$ ), while mean arterial pressure was $93 \pm 3 \mathrm{~mm} \mathrm{Hg}$ (range 74-102 $\mathrm{mm} \mathrm{Hg}$ ). Mean coronary blood flow was $30.6 \pm 3.1 \mathrm{ml} / \mathrm{min}$. None of these values varied significantly during the subsequent experimental interventions. A 5-s coronary artery occlusion resulted in a blood flow debt of $2.55 \pm 0.26 \mathrm{ml}$. Release of the occlusion resulted in a reactive hyperemia $32 \pm 3 \mathrm{~s}$ in duration during which excess arterial inflow of $9.71 \pm 1.42 \mathrm{ml}$ resulted in $375 \pm 20 \%$ blood flow debt repayment (Fig. 1, Table $\mathrm{I}$ ).

When, after a 5-s coronary artery occlusion, the occluder was partially deflated to allow coronary inflow to return to the preocclusion rate and held at this level for $20 \mathrm{~s}$, complete release of the occlusion was followed by an augmented reactive hyperemic response $51 \pm 4 \mathrm{~s}$ in duration during which $15.7 \pm 2.1 \mathrm{ml}$ of excess arterial inflow occurred, resulting in 610 $\pm 45 \%$ blood flow debt repayment (Table I). Both the duration and volume of this response were significantly

${ }^{5}$ Beckman Instruments, Inc., Fullerton, Calif.

- IBM Corp., White Plains, N. Y. 
(A) CONTROL OCCLUSION Debt repayment $=335 \%$
(B) OCCLUSION FOLLOWED BY 20 S RESTRICTION TO CONTROL Debt repayment $=675 \%$

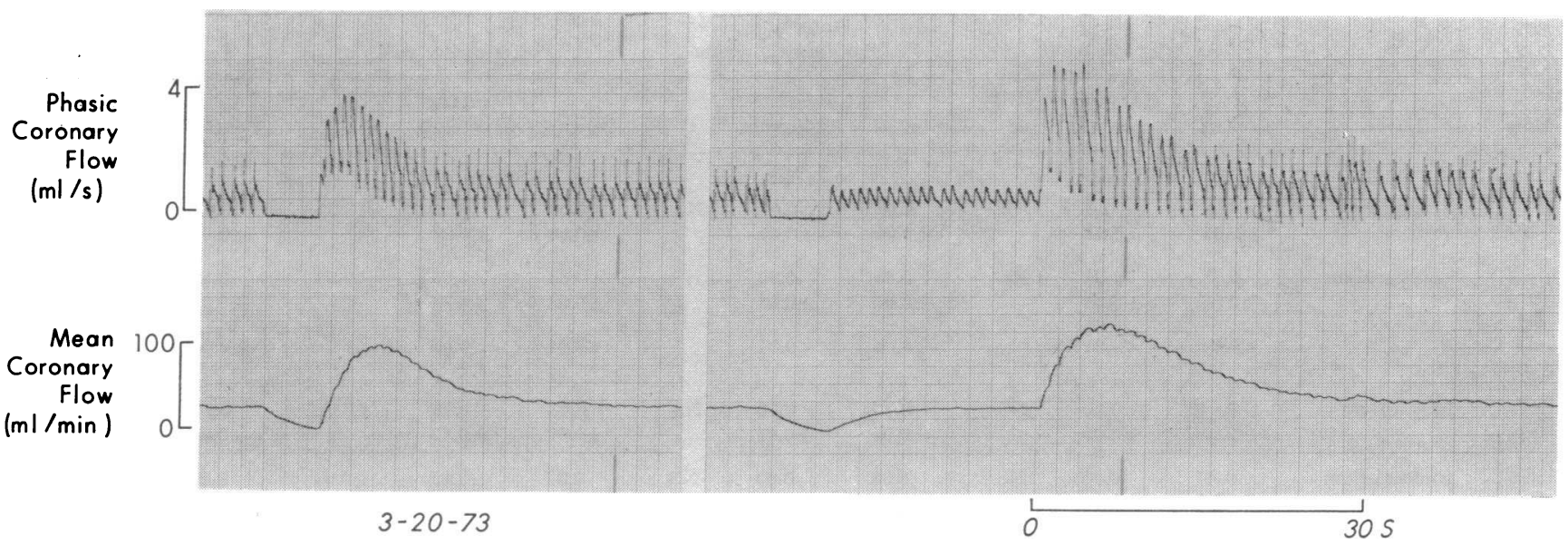

Figure 1 Phasic and mean left circumflex coronary blood flow in a 19-kg awake dog. (A) After a 5-s coronary artery occlusion, a reactive hyperemic response $20 \mathrm{~s}$ in duration resulted in $335 \%$ blood flow debt repayment. (B) When a 5-s occlusion was followed by a 20 -s interval during which coronary artery inflow was restricted to the preocclusion control level, complete release of the occluder resulted in a significantly augmented reactive hyperemic response $32 \mathrm{~s}$ in duration during which excess arterial inflow resulted in $675 \%$ repayment of the blood flow debt.

greater than the reactive hyperemia which followed a control 5-s coronary artery occlusion $(P<0.01)$.

When a 5-s coronary artery occlusion was followed by a 60 -s interval during which coronary inflow was limited to the preocclusion rate, and the occluder then completely released, the subsequent reactive hyperemic responses varied according to the control response after a 5-s occlusion (Table I). In three animals in

TABLE I

Hemodynamic Data

\begin{tabular}{|c|c|c|c|c|c|c|c|c|c|c|c|}
\hline \multirow[b]{2}{*}{ Dog } & \multirow{2}{*}{$\begin{array}{l}\text { Control } \\
\text { coronary } \\
\text { blood } \\
\text { flow }\end{array}$} & \multirow[b]{2}{*}{$\begin{array}{l}\text { Blood } \\
\text { flow } \\
\text { debt }\end{array}$} & \multicolumn{3}{|c|}{$\begin{array}{l}\text { Reactive hyperemia after a } \\
\text { control } 5 \text {-s coronary } \\
\text { artery occlusion }\end{array}$} & \multicolumn{3}{|c|}{$\begin{array}{l}\text { Reactive hyperemia after a 5-s } \\
\text { coronary artery occlusion with } \\
\text { subsequent restriction of } \\
\text { coronary inflow to the } \\
\text { control level for } 20 \mathrm{~s}\end{array}$} & \multicolumn{3}{|c|}{$\begin{array}{l}\text { Reactive hyperemia after a 5-s } \\
\text { coronary artery occlusion with } \\
\text { subsequent restriction of } \\
\text { coronary inflow to the } \\
\text { control level for } 60 \mathrm{~s}\end{array}$} \\
\hline & & & Duration & $\begin{array}{l}\text { Blood } \\
\text { flow } \\
\text { debt }\end{array}$ & Repayment & Duration & $\begin{array}{l}\text { Blood } \\
\text { flow } \\
\text { debt }\end{array}$ & Repayment & Duration & $\begin{array}{l}\text { Blood } \\
\text { flow } \\
\text { debt }\end{array}$ & Repayment \\
\hline & $m l / m i n$ & $m l$ & $s$ & $m l$ & $\%$ & $s$ & $m l$ & $\%$ & $s$ & $m l$ & $\%$ \\
\hline 1 & 26.9 & 2.24 & 43 & 6.27 & 280 & 50 & 7.5 & 335 & 38 & 2.5 & 110 \\
\hline 2 & 26.8 & 2.23 & 23 & 6.58 & 295 & 71 & 10.4 & 465 & - & - & - \\
\hline 3 & 37.9 & 3.16 & 20 & 10.60 & 335 & 32 & 21.3 & 675 & 29 & 8.2 & 260 \\
\hline 4 & 30.8 & 2.57 & 20 & 9.25 & 360 & 30 & 13.4 & 520 & 47 & 7.7 & 300 \\
\hline 5 & 26.9 & 2.24 & 36 & 8.29 & 370 & 64 & 15.3 & 685 & 72 & 16.7 & 745 \\
\hline 6 & 20.9 & 1.74 & 36 & 6.61 & 380 & 54 & 13.5 & 775 & 79 & 12.2 & 700 \\
\hline 7 & 37.8 & 3.15 & 35 & 12.10 & 385 & 51 & 19.9 & 630 & 55 & 10.1 & 320 \\
\hline 8 & 17.0 & 1.42 & 32 & 5.89 & 415 & 42 & 8.5 & 600 & 86 & 29.5 & 1,130 \\
\hline 9 & 31.3 & 2.61 & 29 & 11.50 & 440 & 56 & 20.0 & 765 & 101 & 36.3 & 1,390 \\
\hline 10 & 49.5 & 4.13 & 43 & 20.00 & 485 & 62 & 27.3 & 660 & 105 & 47.5 & 1,150 \\
\hline Mean & 30.6 & 2.55 & 32 & 9.71 & 375 & 51 & 15.7 & 610 & 27 & 19.0 & 680 \\
\hline$\pm \mathrm{SE}$ & \pm 3.1 & \pm 0.26 & \pm 3 & \pm 1.42 & \pm 20 & \pm 4 & \pm 2.1 & \pm 45 & \pm 9 & \pm 5.1 & \pm 150 \\
\hline
\end{tabular}

Dogs are listed in order of increasing blood flow debt repayment observed after the control 5-s coronary artery occlusion. 
TABLE II

Myocardial Blood Flow during Reactive Hyperemia

\begin{tabular}{|c|c|c|c|c|c|c|c|c|c|c|c|c|c|}
\hline \multirow[b]{2}{*}{ King } & \multirow[b]{2}{*}{ Layer } & \multicolumn{3}{|c|}{ Anterior free wall } & \multicolumn{3}{|c|}{$\begin{array}{c}\text { Anterior } \\
\text { Papillary muscle region }\end{array}$} & \multicolumn{3}{|c|}{ Posterior free wall } & \multicolumn{3}{|c|}{$\begin{array}{c}\text { Posterior } \\
\text { Papillary muscle region }\end{array}$} \\
\hline & & Control & $\begin{array}{c}\text { Reactive } \\
\text { hyperemia }\end{array}$ & $P$ & Control & $\begin{array}{c}\text { Reactive } \\
\text { hyperemia }\end{array}$ & $P$ & Control & $\begin{array}{c}\text { Reactive } \\
\text { hyperemia }\end{array}$ & $P$ & Control & $\begin{array}{c}\text { Reactive } \\
\text { hyperemia }\end{array}$ & $P$ \\
\hline \multirow{3}{*}{2} & \multirow[b]{2}{*}{ Epicardium } & \multicolumn{3}{|c|}{$\mathrm{ml} / \mathrm{g} / \min$} & \multicolumn{3}{|c|}{$m l / g / m i n$} & \multicolumn{3}{|c|}{$m l / g / \min$} & \multicolumn{3}{|c|}{$m l / g / m i n$} \\
\hline & & $\begin{array}{r}0.62 \\
\pm 0.05\end{array}$ & $\begin{array}{r}0.63 \\
\pm 0.05\end{array}$ & NS & $\begin{array}{r}0.62 \\
\pm 0.06\end{array}$ & $\begin{array}{r}0.67 \\
\pm 0.06\end{array}$ & NS & $\begin{array}{r}0.60 \\
\pm 0.06\end{array}$ & $\begin{array}{r}0.83 \\
\pm 0.07\end{array}$ & $<0.01$ & $\begin{array}{r}0.65 \\
\pm 0.07\end{array}$ & $\begin{array}{r}1.06 \\
\pm 0.12\end{array}$ & $<0.01$ \\
\hline & Endocarcium & $\begin{array}{r}0.75 \\
\pm 0.05\end{array}$ & $\begin{array}{r}0.76 \\
\pm 0.05\end{array}$ & NS & $\begin{array}{r}0.81 \\
\pm 0.07\end{array}$ & $\begin{array}{r}0.92 \\
\pm 0.07\end{array}$ & NS & $\begin{array}{r}0.83 \\
\pm 0.08\end{array}$ & $\begin{array}{r}1.65 \\
\pm 0.22\end{array}$ & $<0.02$ & $\begin{array}{r}0.82 \\
\pm 0.08\end{array}$ & $\begin{array}{r}1.86 \\
\pm 0.27\end{array}$ & $<0.02$ \\
\hline \multirow{3}{*}{3} & $P$ & $<0.01$ & $<0.01$ & & $<0.01$ & $<0.01$ & & $<0.01$ & $<0.02$ & & $<0.01$ & $<0.04$ & \\
\hline & Epicardium & $\begin{array}{r}0.61 \\
\pm 0.05\end{array}$ & $\begin{array}{r}0.60 \\
\pm 0.06\end{array}$ & NS & $\begin{array}{r}0.70 \\
\pm 0.07\end{array}$ & $\begin{array}{r}0.70 \\
\pm 0.05\end{array}$ & NS & $\begin{array}{r}0.68 \\
\pm 0.09\end{array}$ & $\begin{array}{r}0.98 \\
\pm 0.13\end{array}$ & $<0.01$ & $\begin{array}{r}0.76 \\
\pm 0.06\end{array}$ & $\begin{array}{r}1.04 \\
\pm 0.15\end{array}$ & $<0.05$ \\
\hline & $\begin{array}{l}\text { Endocardium } \\
P\end{array}$ & $\begin{array}{r}0.70 \\
\pm 0.06 \\
<0.05\end{array}$ & $\begin{array}{r}0.76 \\
\pm 0.05 \\
<0.01\end{array}$ & NS & $\begin{array}{r}0.88 \\
\pm 0.08 \\
<0.01\end{array}$ & $\begin{array}{r}0.93 \\
\pm 0.06 \\
<0.01\end{array}$ & NS & $\begin{array}{c}0.82 \\
\pm 0.12 \\
\text { NS }\end{array}$ & $\begin{array}{c}1.25 \\
\pm 0.26 \\
\text { NS }\end{array}$ & $<0.01$ & $\begin{array}{c}0.80 \\
\pm 0.09 \\
\text { NS }\end{array}$ & $\begin{array}{r}1.82 \\
\pm 0.33 \\
<0.05\end{array}$ & $<0.04$ \\
\hline
\end{tabular}

Flow measurements were performed by injecting radionuclide-labeled microspheres into the left atrium during resting control conditions and during the reactive hyperemia after complete release of a 5 -s occlusion of the left circumflex coronary artery. NS = no statistically significant difference.

which the reactive hyperemia after a control 5-s coronary artery occlusion resulted in $360 \%$ or less blood flow debt repayment, the blood flow debt repayment after a 5-s coronary occlusion followed by a 60-s restriction of coronary inflow to the control level was less than that after a control 5-s coronary artery occlu-

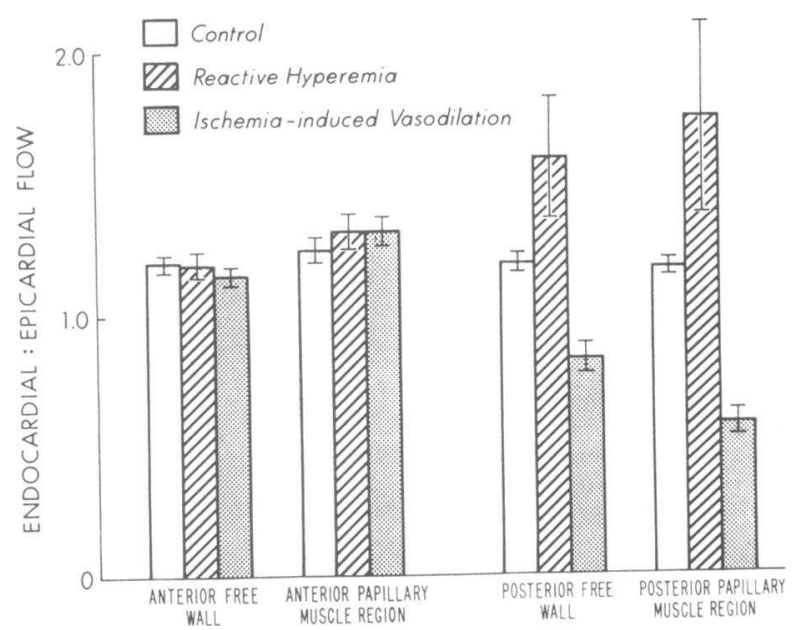

FIgURE 2 The ratio of endocardial to epicardial flow during control conditions in 10 dogs, during reactive hyperemia after a 5-s occlusion of the circumflex branch of the left coronary artery in seven dogs, and during an interval of ischemia-induced vasodilation when a 5-s coronary artery occlusion was followed by restriction of arterial inflow to the preocclusion control rate. Bars represent mean values for rings 2 and 3 . The posterior free wall and posterior papillary muscle regions represent areas perfused by the left circumflex coronary artery, and consequently the regions under study. The corresponding anterior regions served as controls. Values are mean \pm SEM. sion. In contrast to this, in three animals in which the reactive hyperemia after a control 5-s occlusion resulted in $415 \%$ or greater blood flow debt repayment, the reactive hyperemia after a 5-s occlusion followed by a 60 -s restriction of coronary inflow to the control level was significantly greater than either the control response or the response which occurred when a 5-s occlusion was followed by: restriction of inflow to the control level for $20 \mathrm{~s}$. In three animals in which control 5-s coronary artery occlusions resulted in reactive hyperemic responses with blood flow debt repayments of $370-385 \%$, the reactive hyperemia subsequent to a 5 -s coronary occlusion followed by 60 -s restriction of inflow to the control rate was variable (Table I).

Evaluation of the phasic pattern of coronary flow revealed that during control conditions mean coronary flow during systole was $4.0 \pm 0.6 \mathrm{ml} / \mathrm{min}$ whereas mean flow during diastole was $26.6 \pm 2.7 \mathrm{ml} / \mathrm{min}$, so that $13 \pm 1.3 \%$ of flow occurred during systole. During the interval when arterial inflow was restricted to the control rate after a 5-s coronary occlusion, the flow pattern was altered so that mean systolic flow increased to 8.2 $\pm 0.7 \mathrm{ml} / \mathrm{min}$ (mean change $=+105 \%, P<0.01$ ), while diastolic flow decreased to $23.2 \pm 2.5 \mathrm{ml} / \mathrm{min}$ (mean change $=-13 \%, P<0.01$ ). During this interval of restricted inflow, $26 \pm 1.9 \%$ of the total flow occurred during systole.

Regional myocardial blood flow during control conditions and during the reactive hyperemia after a 5-s occlusion of the left circumflex coronary artery in seven dogs is shown in Table II. In the anterior free wall and anterior papillary muscle regions which served as controls, epicardial flow ranged from 0.61 
TABLE III

Myocardial Blood Flow during Ischemia-Induced Coronary Vasodilation

\begin{tabular}{|c|c|c|c|c|c|c|c|c|c|c|c|c|c|}
\hline \multirow[b]{2}{*}{ Ring } & \multirow[b]{2}{*}{ Layer } & \multicolumn{3}{|c|}{ Anterior free wall } & \multicolumn{3}{|c|}{$\begin{array}{c}\text { Anterior } \\
\text { Papillary muscle region }\end{array}$} & \multicolumn{3}{|c|}{ Posterior free wall } & \multicolumn{3}{|c|}{$\begin{array}{c}\text { Posterior } \\
\text { Papillary muscle region }\end{array}$} \\
\hline & & Control & $\begin{array}{l}\text { Ischemia- } \\
\text { induced } \\
\text { vaso- } \\
\text { dilation }\end{array}$ & $P$ & Control & $\begin{array}{l}\text { Ischemia- } \\
\text { induced } \\
\text { vaso- } \\
\text { dilation }\end{array}$ & $P$ & Control & $\begin{array}{l}\text { Ischemia- } \\
\text { induced } \\
\text { vaso- } \\
\text { dilation }\end{array}$ & $P$ & Control & $\begin{array}{l}\text { Ischemia- } \\
\text { induced } \\
\text { vaso- } \\
\text { dilation }\end{array}$ & $P$ \\
\hline \multirow{3}{*}{2} & \multirow[b]{2}{*}{ Epicardium } & \multicolumn{3}{|c|}{$m l / g / m i n$} & \multicolumn{3}{|c|}{$m l / g / m i n$} & \multicolumn{3}{|c|}{$m l / g / m i n$} & \multicolumn{3}{|c|}{$\mathrm{ml} / \mathrm{g} / \mathrm{min}$} \\
\hline & & $\begin{array}{r}0.70 \\
\pm 0.03\end{array}$ & $\begin{array}{r}0.62 \\
\pm 0.07\end{array}$ & NS & $\begin{array}{r}0.71 \\
\pm 0.07\end{array}$ & $\begin{array}{r}0.66 \\
\pm 0.06\end{array}$ & NS & $\begin{array}{r}0.64 \\
\pm 0.02\end{array}$ & $\begin{array}{r}0.77 \\
\pm 0.05\end{array}$ & $<0.03$ & $\begin{array}{r}0.76 \\
\pm 0.05\end{array}$ & $\begin{array}{r}0.91 \\
\pm 0.08\end{array}$ & $<0.01$ \\
\hline & Endocardium & $\begin{array}{r}0.84 \\
\pm 0.04\end{array}$ & $\begin{array}{r}0.80 \\
\pm 0.05\end{array}$ & NS & $\begin{array}{r}0.89 \\
\pm 0.06\end{array}$ & $\begin{array}{r}0.84 \\
\pm 0.06\end{array}$ & NS & $\begin{array}{r}0.82 \\
\pm 0.05\end{array}$ & $\begin{array}{r}0.70 \\
\pm 0.05\end{array}$ & $<0.01$ & $\begin{array}{r}0.89 \\
\pm 0.06\end{array}$ & $\begin{array}{r}0.54 \\
\pm 0.04\end{array}$ & $<0.01$ \\
\hline \multirow{4}{*}{3} & $P$ & $<0.01$ & $<0.01$ & & $<0.01$ & $<0.01$ & & $<0.01$ & NS & & $<0.01$ & $<0.01$ & \\
\hline & Epicardium & $\begin{array}{r}0.68 \\
\pm 0.05\end{array}$ & $\begin{array}{r}0.64 \\
\pm 0.05\end{array}$ & NS & $\begin{array}{r}0.73 \\
\pm 0.08\end{array}$ & $\begin{array}{r}0.64 \\
\pm 0.05\end{array}$ & NS & $\begin{array}{r}0.71 \\
\pm 0.05\end{array}$ & $\begin{array}{r}0.87 \\
\pm 0.06\end{array}$ & $<0.04$ & $\begin{array}{r}0.78 \\
\pm 0.05\end{array}$ & $\begin{array}{r}0.89 \\
\pm 0.08\end{array}$ & $<0.01$ \\
\hline & Endocardium & $\begin{array}{r}0.78 \\
\pm 0.05\end{array}$ & $\begin{array}{r}0.74 \\
\pm 0.04\end{array}$ & NS & $\begin{array}{r}0.93 \\
\pm 0.08\end{array}$ & $\begin{array}{r}0.87 \\
\pm 0.07\end{array}$ & NS & $\begin{array}{r}0.76 \\
\pm 0.08\end{array}$ & $\begin{array}{r}0.70 \\
\pm 0.06\end{array}$ & $<0.01$ & $\begin{array}{r}0.88 \\
\pm 0.05\end{array}$ & $\begin{array}{r}0.52 \\
\pm 0.04\end{array}$ & $<0.01$ \\
\hline & $P$ & $<0.01$ & $<0.01$ & & $<0.02$ & $<0.01$ & & $<0.01$ & $<0.01$ & & $<0.04$ & $<0.01$ & \\
\hline
\end{tabular}

Flow measurements were performed by injecting radionuclide-labeled microspheres into the left atrium during resting control conditions and $5 \mathrm{~s}$ after release of a 5 - $\mathrm{s}$ Fow me preocclusion rate for $45 \mathrm{~s}$ after release of the 5-s total occlusion to insure complete dispersion of microspheres before complete release of the occluder. NS = no statistically significant difference.

to $0.70 \mathrm{ml} / \mathrm{g} / \mathrm{min}$, while endocardial flow ranged from 0.70 to $0.88 \mathrm{ml} / \mathrm{g} / \mathrm{min}$. During both control conditions and reactive hyperemia, endocardial flow was significantly greater than epicardial flow in all regions, re- sulting in an endocardial: epicardial flow ratio which was significantly greater than unity $(P<0.05)$ (Fig. $2)$. Blood flow in the anterior control regions during reactive hyperemia in the left circumflex coronary bed

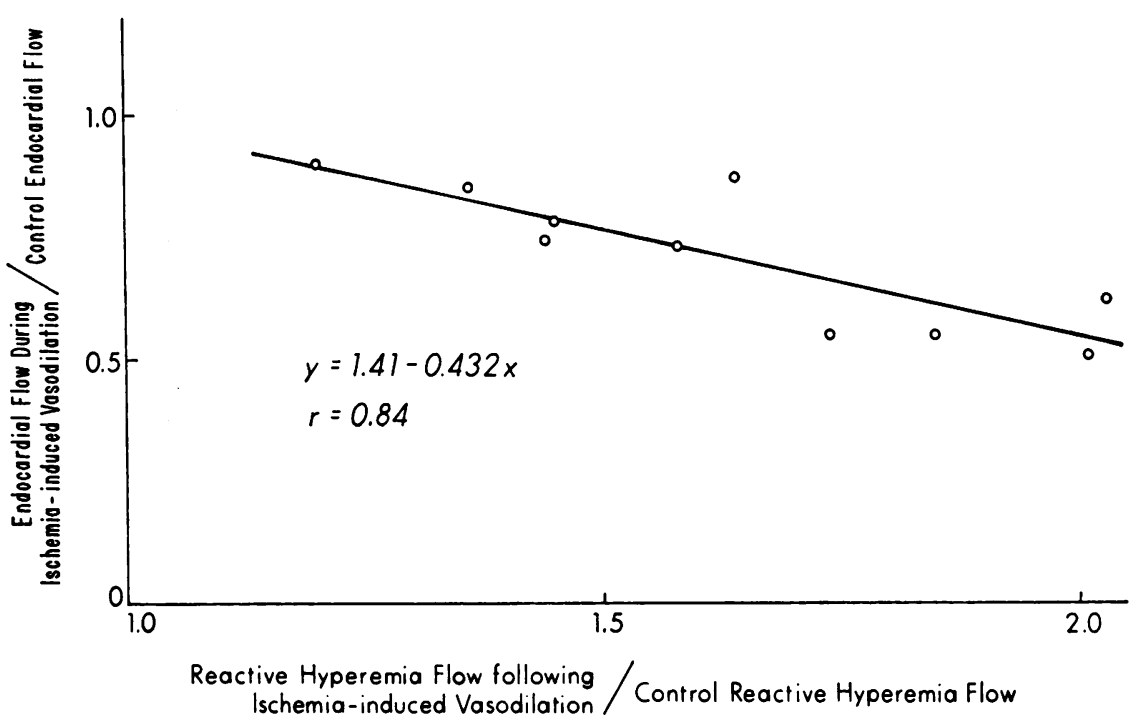

FIGURE 3 On the abscissa is plotted the increase in reactive hyperemic flow which occurred when a 5-s left circumflex coronary artery occlusion was followed by a 20 -s interval during which arterial inflow was held at the preocclusion control level as compared with a control reactive hyperemia after a simple 5-s coronary artery occlusion. On the ordinate is plotted the relative change in endocardium: epicardium blood flow ratio observed in the posterior free wall and posterior papillary muscle regions when coronary artery inflow was held to the preocclusion control rate during coronary vasodilation induced by a 5-s occlusion of the left circumflex coronary artery. Data obtained from 10 unanesthetized dogs. 
was not significantly different from that observed during control conditions.

During control conditions myocardial blood flow in the posterior free wall and posterior papillary muscle region specimens was not significantly different from that in the corresponding anterior specimens (Table II). During reactive hyperemia, both epicardial and endocardial flow were significantly greater than control in both posterior free wall and posterior papillary muscle regions. However, the mean increase in epicardial flow during reactive hyperemia (mean change $=+46 \pm 7 \%$ ) was significantly less than the increase in endocardial flow (mean change $=+101 \pm 31 \%)(P$ $<0.01)$. Consequently, the mean ratios of endocardial to epicardial flow during reactive hyperemia were significantly greater than control in both the posterior free wall and posterior papillary muscle specimens ( $P$ $<0.01$ ) (Fig. 2)

Data obtained during control conditions and when microsphere injections were made while coronary inflow was restricted to the preocclusion rate after a 5-s occlusion of the left circumflex coronary artery in 10 dogs are shown in Table III. Again, during the control situation mean endocardial flows were significantly greater than mean epicardial flows, resulting in endocardium: epicardium flow ratios significantly greater than unity $(P<0.04)$. When coronary flow was restricted to the control rate during coronary vasodilation induced by a 5-s coronary occlusion, mean epicardial flow in the posterior free wall and posterior papillary muscle regions was increased $20 \pm 3 \%$ above the control value $(P<0.01)$. In contrast to this, mean endocardial flow within these posterior regions under study was decreased $26 \pm 4 \%$ below the control level $(P<$ $0.01)$. Consequently, the ratio of endocardial to epicardial flow was significantly decreased below the control level and below unity in the regions under study $(P<0.01$ ) (Fig. 2).

These data indicate that although arterial inflow was at the preocclusion control level, coronary vasodilation after a 5-s coronary artery occlusion resulted in significant redistribution of myocardial blood flow with increased flow to the subepicardial myocardium at the expense of decreased flow to the subendocardium. To evaluate whether the redistribution of myocardial blood flow was in fact correlated with the augmentation of the reactive hyperemic response, the relative reduction of endocardial flow during ischemia-induced vasodilation was plotted against the relative increase in volume of reactive hyperemic flow which occurred when a 5 -s occlusion was followed by a 20 -s restriction of arterial inflow to the control level. As shown in Fig. 3, a significant correlation existed between these variables, indicating that the increased reactive hyper- emia was related to the degree of underperfusion of the subendocardium which occurred during the period of ischemia-induced vasodilation when coronary inflow was restricted to the preocclusion control rate.

\section{DISCUSSION}

Because the present study was designed to evaluate the intrinsic response of the coronary vasculature to ischemia, intervals of total coronary occlusion were limited to $5 \mathrm{~s}$ in duration. Occlusions of this duration elicit a marked coronary vasodilator response without producing the alterations of arterial pressure, heart rate, and sympathetic nervous system activity which may occur with occlusions of longer duration (12). Changes of these associated hemodynamic variables are capable of directly influencing coronary blood flow and were thus avoided in the present study.

Previous studies have demonstrated that during total coronary artery occlusion in the dog a modest inflow of arterial blood to the distal myocardium continues via pre-existing epicardial collateral channels $(13,14)$. This inflow, which generally does not exceed $25 \%$ of the normal antegrade arterial inflow before occlusion, is preferentially delivered to the subepicardial myocardium, thus resulting in a gradient of ischemia during occlusion, with ischemia in the subendocardial myocardium more severe than in the subepicardial myocardium (15). It was consequently not unexpected that administration of microspheres during reactive hyperemia demonstrated significantly greater flow to the subendocardial layer of myocardium. Thus, the augmented arterial inflow appeared to be delivered in proportion to the degree of ischemia produced by the preceding arterial occlusion. It should be noted that values obtained when microspheres were injected $5 \mathrm{~s}$ after complete release of a coronary artery occlusion do not represent steady-state measurements, but rather provide only a single instantaneous estimation of myocardial blood flow corresponding approximately to the maximum flow response measured by the electromagnetic flowmeter. Thus, this single measurement does not represent mean flow during the entire reactive hyperemic period, but rather corresponds to flow during the peak of the reactive hyperemia. This injection of microspheres during unimpeded coronary flow was performed to allow comparison with the subsequent study in which microspheres were injected at an identical interval after coronary artery occlusion but while coronary inflow was held to the preocclusion control rate.

In the coronary circulation the reactive hyperemic response has been shown to be exquisitely sensitive to the myocardial metabolic activity during the interval of arterial occlusion $(6,7)$. Thus, increases of myo- 
cardial oxygen consumption are accompanied by commensurate increases of the reactive hyperemic response to maintain a constant blood flow debt repayment (6). Similarly, increases in the duration of arterial occlusion produced increases in the reactive hyperemic response to maintain an essentially constant blood flow debt repayment (16). Since reactive hyperemia bears a constant quantitative relationship to the degree of preceding ischemia, it seems reasonable that the magnitude of the reactive hyperemic response could be utilized to quantitatively assess the degree of preceding ischemia.

When, after a 5-s occlusion in the present study, coronary inflow was held at the preocclusion level for $20 \mathrm{~s}$, final complete release of the occluder was followed by a reactive hyperemia markedly augmented above that following a simple 5-s coronary artery occlusion. This finding suggested that ischemia was continuing after release of the complete occlusion during the interval when coronary inflow was held at the preocclusion rate. However, inflow during this interval was at a level which had been sufficient to sustain myocardial metabolic activity before application of the occlusion. Why should not this same volume of arterial inflow be adequate to sustain myocardial metabolic activity subsequent to a brief total coronary artery occlusion? If the coronary vasodilation resulting from the 5-s complete occlusion compromised the ability of active coronary vasomotion to effect normal distribution of myocardial blood flow, then redistribution of flow might occur, resulting in some areas of hyperemia at the expense of ischemia continuing in other areas. The result would be regional ischemia in the presence of normal net arterial inflow. The coincidence of regional myocardial ischemia in parallel with regional hyperemia : would be expected to increase the reactive hyperemic response when the arterial occlusion was finally completely released, since in the coronary circulation blood flow debts are normally discharged at a rate to effect repayments of $300-600 \%$ of the preceding debt. Thus, the fact that the reactive hyperemic response in the coronary circulation normally meters inflow of excess arterial blood three to six times the blood flow debt implies that if hyperemia and ischemia occur in parallel during restricted arterial inflow, a net blood flow debt will continue to accumulate.

That this proposed redistribution of myocardial blood flow did in fact occur was shown by the flow measurements obtained during the interval when the coronary vasculature was dilated but arterial inflow was limited to the control rate. Whereas in the control situation the subendocardial muscle received slightly more blood than the subepicardial myocardium, and during unimpeded reactive hyperemia subendocardial flow was further increased, during the interval of coronary vasodilation when arterial inflow was held at the preocclusion rate, blood flow to the subendocardial layer was markedly reduced while flow to the subepicardial muscle was increased above the control rate. Since the resolution provided by dividing the left ventricular wall into only two layers is very poor, it is probable that areas of much less and much greater flow rates existed within each of the samples obtained. Further subdivision of the left ventricular wall was not done, since use of smaller myocardial samples would have resulted in the number of microspheres per specimen, especially in areas of low flow, falling below the level at which random distribution error of the microsphere technique becomes intolerable (17).

Previous studies have demonstrated that when coronary blood flow is reduced below the nutritional requirement of the myocardium, the resultant ischemia is not uniformly distributed across the wall of the ventricle. Rather, flow tends to be maintained in the subepicardial myocardium while in the subendocardial myocardium flow is decreased and biochemical indications of ischemia appear (19-21). Buckberg, Fixler, Archie, and Hoffman (18) have demonstrated in openchest dogs that interventions which interfere with normal diastolic coronary perfusion while simultaneously increasing myocardial oxygen requirements such as creation of large systemic arteriovenous fistulas to markedly decrease aortic diastolic pressure, rapid ventricular pacing to decrease the duration of diastole, and constriction of the ascending aorta to increase left ventricular diastolic pressure may result in subendocardial underperfusion despite normal or increased total coronary artery inflow. During these interventions, the phasic pattern of coronary flow was altered so that the major portion of flow occurred during systole, unlike the normal situation where coronary flow is predominantly diastolic. In the present study, when coronary flow was restricted to the preocclusion level after a 5-s occlusion, the phasic flow pattern was altered so that coronary flow took on the configuration of arterial pressure. This is the pattern of phasic flow that would be expected if the major resistance to flow resided at a proximal fixed stenotic orifice rather than at the small vessel level as normally obtains. This alteration of the phasic pattern of coronary flow was accompanied by a modest shift of flow from diastole to systole, so that mean coronary inflow during diastole was decreased by $13 \%$.

In the normal situation, it appears that arterial inflow to the subendocardial myocardium ceases during systole, since systolic tissue pressure within the subendocardium equals or exceeds coronary driving pressure (1-3). Adequate subendocardial perfusion consequently 
depends upon a perfusion gradient favoring the subendocardium during diastole (4). Maintenance of this perfusion gradient requires lower coronary vascular resistance in the subendocardium than in the subepicardium, and sufficient diastolic intraarterial perfusion pressure to deliver blood in proportion to the gradient of vascular resistance. In the present study, when microspheres were injected during the reactive hyperemia $5 \mathrm{~s}$ after complete release of a 5-s coronary artery occlusion, flow to the subendocardium markedly exceeded flow to the subepicardium, indicating considerably less resistance to flow in the subendocardium than in the subepicardium. Nevertheless, microspheres injected at an identical interval after coronary occlusion while inflow was restricted to the preocclusion level demonstrated a marked shift of flow away from the subendocardium. Although the alteration of the pattern of phasic flow during restricted coronary inflow resulted in a $13 \%$ decrease in the absolute quantity of arterial inflow during diastole, this decrease of diastolic inflow was less than the simultaneous decrease of vascular resistance within the subendocardium and consequently would seem inadequate to explain the observed redistribution of flow away from the subendocardium.

Although coronary perfusion pressure distal to the subtotal coronary artery occlusion could not be measured in the awake dogs used in the present study, it is interesting to speculate whether alterations of the distal perfusion pressure during restricted coronary inflow could have contributed to the observed redistribution of myocardial blood flow. In the presence of a proximal coronary artery stenosis, normal subendocardial perfusion may be maintained if the distal coronary vascular resistance is high relative to the resistance offered by the proximal stenotic lesion. In this situation, coronary flow will be limited not by the proximal stenosis, but rather by the peripheral coronary vascular resistance, so that little pressure drop will occur across the proximal stenosis and diastolic coronary perfusion pressure will be maintained high. If, on the other hand, the distal coronary vascular resistance is low relative to the proximal stenosis, a large pressure drop will occur across the proximal stenosis, and the perfusion pressure distal to the stenosis will be low. If perfusion pressure falls, it is likely that the ability to maintain a normal diastolic flow gradient favoring the subendocardium will fail, and subendocardial ischemia will occur. It is clear that a relative balance between the degree of proximal stenosis and distal coronary vascular resistance exists. Although it is well recognized that increasing the proximal stenotic lesion will result in subendocardial ischemia (19-21), the present data indicate that reduction of peripheral coronary vascular resistance in the presence of a flow-limiting coronary artery stenosis can also result in selective subendocardial ischemia.

The concept of "coronary steal" was first introduced by Effler, Sheldon, Turner, and Groves (22) to describe a situation in which coronary flow is "stolen" from a normally connected coronary artery and delivered via intercoronary collateral vessels to a coronary artery which is anomalously connected to a low-pressure cardiac chamber or pulmonary artery. Subsequently, the concept of coronary steal has been used to postulate flow between coronary arteries interconnected by collateral channels distal to obstructive coronary artery atherosclerotic lesions (23). It has been proposed that vasodilation of resistance vessels in a coronary bed from which collateral channels originate would result in preferential flow into the dilated resistance vessels and away from the collateral vessels (23). In this way, arterial blood would be stolen from the vascular bed which depended on collateral channels for its arterial supply as the pressure in the large coronary artery falls in response to opening of resistance vessels within that bed. The present study, however, suggests an alternative mechanism by which shunting of blood away from the subendocardial myocardium might occur which is not dependent upon the presence of intercoronary collateral channels, but which rather appears to be a function of normal coronary anatomy and physiology. Thus, vasodilation of the resistance vessels distal to a flow-limiting coronary artery obstruction may result in redistribution of myocardial blood flow with production of subendocardial ischemia in the presence of a net volume of arterial inflow, which, if properly distributed, would be adequate to prevent myocardial ischemia.

The mechanisms involved in precipitation of clinical acute myocardial infarction are not entirely clear. Although nearly all hearts of patients dying from acute infarction have diffuse, occlusive atherosclerotic coronary artery disease, at least half have no demonstrable evidence of acute coronary occlusion $(22,23)$. It is not clear why, in the absence of acute occlusion, the chronically diseased coronary arteries suddenly become unable to supply sufficient arterial inflow to maintain the distal myocardium. It is of interest that myocardial infarction occurring in the absence of demonstrable acute coronary occlusion is especially likely to be subendocardial in location $(24,25)$. The present data suggest a possible mechanism by which coronary vasodilation distal to a flow-limiting coronary artery stenosis may result in subendocardial ischemia in the presence of a normal volume of coronary inflow. It is possible that this redistribution of myocardial blood 
flow may at times be self-perpetuating. It is likely that any cause of vasodilation distal to a flow-limiting stenosis would result in redistribution of flow, producing subendocardial ischemia which in turn would result in further vasodilation. In response to ischemia, the coronary vessels normally meter excess arterial inflow which is three to six times the preceding blood flow debt before coronary vascular tone is regained. In the presence of a proximal arterial stenosis, however, arterial inflow may be prevented from increasing sufficiently to effect this degree of debt repayment. In this situation, the continuing vasodilation would be expected to result in continuing redistribution of myocardial blood flow which in turn would result in continuing subendocardial ischemia. Thus, the marked vasodilator response of the coronary vasculature to ischemia provides a positive feedback mechanism whereby, in the presence of a proximal flow-limiting coronary artery stenosis, ischemia may be perpetuated despite a normal volume of arterial flow.

Whether this mechanism is in fact significant may be related to the reactivity of the coronary vascular bed to ischemia. Thus, in the present study, when 5-s occlusions led to reactive hyperemic responses with blood flow debt repayments of $280-360 \%$, holding coronary inflow to the preocclusion rate for $60 \mathrm{~s}$ after a 5 -s occlusion resulted in a hyperemic response less than that after a simple 5-s occlusion. In these dogs, coronary vascular tone appeared to be recovering during the 60-s interval of restricted inflow. However, in dogs in which 5-s occlusions were followed by blood flow debt repayments of $415 \%$ or greater, holding coronary inflow to the preocclusion level for $60 \mathrm{~s}$ after a 5 -s occlusion resulted in marked augmentation of the reactive hyperemic response. These data suggest that individual variations in the responsiveness of the coronary vasculature to ischemia may determine whether ischemia not satisfied by the usual increase of coronary arterial inflow will result in continuing vasodilation and redistribution of flow with perpetuation of the ischemia, or whether coronary vascular tone will be regained without the usual excess volume of arterial inflow. It is possible that these differences in the response to ischemia may in part have been conditioned by individual variations in the extent of innate intercoronary collateral circulation. Although no animal had sufficient coronary collateral circulation to prevent significant S-T elevation during a 60 -s coronary artery occlusion, it is possible that collateral inflow in some animals may nevertheless have been sufficient to facilitate partial recovery of coronary vascular tone within the 60-s interval and thus blunt the subsequent reactive hyperemic response.

\section{ACKNOWLEDGMENTS}

The authors wish to acknowledge the valuable assist.nce provided by the following individuals: Mr. hirvy Luper, Mr. Eric Fields, and Mr. James Ferrell for expert tic..nical assistance; Mr. J. Mic.ıael Taylor and uis stait at tıle Durnam veterans Administration Hospital Animal Lare Facility; Mr. Dunald G. Powell of tne Lurıam veter..ns Administration Hospital Medical Illustration Department; and Miss Brenda Clement and Mrs. Rosa Eturidge for secretarial assistance.

This work was supported in part by NIH grant HL16438 from the U. S. Public Health Service, V. A. Project no. $0517-01$.

\section{REFERENCES}

1. Kirk, E. S., and C. R. Honig. 1964. Experimental and theoretical analysis of myocardial tissue pressure. $A m$. J. Physiol. 207: 361-367.

2. Armour, J. A., and W. C. Randall. 1971. Canine left ventricular intramyocardial pressures. Am. J. Physiol. 220 : $1833-1839$.

3. Downey, J. M., and E. S. Kirk. 1974. Distribution of the coronary blood flow across the canine heart wall during systole. Circ. Res. 34: 251-257.

4. Moir, T. W. 1972. Subendocardial distribution of coronary blood flow and the effect of antianginul drugs. Circ. Res. 30: 621-627.

5. Provenza, D. V., and S. Scherlis. 1959. Coronary circulation in the dog's heart: demonstration of muscle sphincters in capillaries. Circ. Res. $7: 318-324$.

6. Bache, R. J., F. R. Cobb, and J. C. Greenfield, Jr. 1973. Effects of increased myocardial oxygen consumption on coronary reactive hyperemia in the dog. Circ. Res. 33: 588-596.

7. Pauly, T. J., W. C. Zarnstorff, and N. Bittar. 1973. Myocardial metabolic activity as a determinant of reactive hyperaemia responses in the dog heart. Cardiovasc. Res. 7 : 90-94.

8. Alexander, J. A., W. C. Sealy, and J. C. Greenfield, Jr. 1969. Improved technique for implanting electromagnetic flowmeter probes on the coronary artery. $J$. Appl. Physiol. 27 : 139-140.

9. Debley, V. G. 1971. Miniature hydraulic occluder for zero blood flow determination. J. Appl. Physiol. 31: 138-139.

10. Freeman, N. E. 1935. Effect of temperature on the rate of blood flow in the normal and in the sympathectomized hand. Am. J. Physiol. 113: 384-398.

11. Cobb, F. R., R. J. Bache, and J. C. Greenfield, Jr. 1974. Regional myocardial blood flow in awake dogs. J. Clin. Invest. 53: 1618-1625.

12. Pauly, T. J., and N. Bittar. 1971. Myocardial reactive hyperaemia responses in the dog after beta receptor block with propranolol. Cardiovasc. Res. 5: 440-443.

13. Eckstein, R. W., D. E. Gregg, and W. H. Pritchard. 1941. The magnitude and time of development of the collateral circulation in occluded femoral, carotid and coronary arteries. Am. J. Physiol. 132: 351-361.

14. Cibulski, A. A., P. H. Lehan, and H. K. Hellems. 1973. Myocardial collateral flow measurements in mongrel dogs. Am. J. Physiol. 225: 559-565.

15. Becker, L. C., N. J. Fortuin, and B. Pitt. 1971. Effect of ischemia and antianginal drugs on the distribution 
of radioactive microspheres in the canine left ventricle Circ. Res. 28: 263-269.

16. Olsson, R. A., and D. E. Gregg. 1965. Myocardial reactive hyperemia in the unanesthetized dog. Am. J. Physiol. 208: 224-230.

17. Buckberg, G. D., J. D. Luck, B. Payne, J. I. E. Hoffman, J. P. Archie, and D. E. Fixler. 1971. Some sources of error in measuring regional blood flow with radioactive microspheres. J. Appl. Physiol. 31: 598-604.

18. Buckberg, G. D., D. E. Fixler, J. P. Archie, and J. I. E. Hoffman. 1972. Experimental subendocardial ischemia in dogs with normal coronary arteries. Circ. Res. 30 67-81.

19. Salisbury, P. F., C. E. Cross, and P. A. Rieben. 1963 Acute ischemia of inner layers of ventricular wall. $\mathrm{Am}$. Heart J. 66: 650-656.

20. Moir, T. W., and D. W. DeBra. 1967. Effect of left ventricular hypertension, ischemia and vasoactive drugs on the myocardial distribution of coronary flow. Circ. Res. 21 : 65-74.

21. Griggs, D. M., Jr., V. V. Tchokoev, and C. C. Chen 1972. Transmural differences in ventricular tissue substrate levels due to coronary constriction. Am. J. Physiol. 222 : 705-709.

22. Effler, D. B., W. C. Sheldon, J. J. Turner, and L. K. Groves. 1967. Coronary arteriovenous fistulas: diagnosis and surgical management. Report of fifteen cases. Surgery (St. Louis.). 61: 41-50.

23. Rowe, G. G. 1970. Inequalities of myocardial perfusion in coronary artery disease ("coronary steal"). Circulation. 42: 193-194.

24. Edwards, J. E. 1971. The value and limitations of necropsy studies in coronary arterial disease. Progr. Cardiovasc. Dis. 13: 309-323.

25. Roberts, W. C. 1972. Coronary arteries in fatal acute myocardial infarction. Circulation. 45: 215-230.

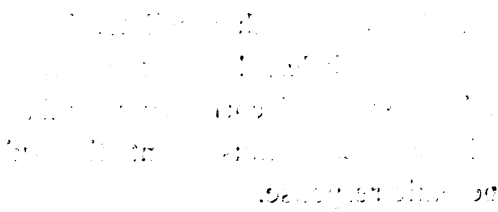

